\title{
Examining the Factors Associated with Paid Employment of Clients Enrolled in First Episode of Psychosis Programs
}

\author{
Carolyn S. Dewa, ${ }^{1,2}$ Lucy Trojanowski, ${ }^{1}$ Chiachen Cheng, ${ }^{1,3}$ and Desmond Loong ${ }^{1}$ \\ ${ }^{1}$ Centre for Research on Employment and Workplace Health, Centre for Addition and Mental Health, 455 Spadina Avenue, Suite 300, \\ Toronto, ON, Canada M5S 2G8 \\ ${ }^{2}$ Department of Psychiatry, University of Toronto, 250 College Street, Toronto, ON, Canada M5T 1R8 \\ ${ }^{3}$ Clinic \& Resource Centre, Canadian Mental Health Association, 272 Park Avenue, Thunder Bay, ON, Canada P7B 1C5
}

Correspondence should be addressed to Carolyn S. Dewa, carolyn_dewa@camh.net

Received 14 October 2011; Revised 27 April 2012; Accepted 29 April 2012

Academic Editor: Eóin Killackey

Copyright () 2012 Carolyn S. Dewa et al. This is an open access article distributed under the Creative Commons Attribution License, which permits unrestricted use, distribution, and reproduction in any medium, provided the original work is properly cited.

\begin{abstract}
Schizophrenia is one of the most debilitating mental disorders. For a significant portion of individuals who suffer from this disorder, onset occurs in young adulthood, arresting important social and educational development that is necessary for future successful labor force participation. The purpose of this paper is to contribute to the literature about clients enrolled in first episode psychosis programs and psychosocial outcomes by examining the factors associated with paid employment among young adults who have experienced their first psychotic episodes. In this paper, we consider the association of socioeconomic factors to employment. Our results suggest that in addition to treatment, socioeconomic factors such as receipt of public disability benefits and educational attainment are associated with employment status. These results can help to inform future directions for the enhancement of psychosocial programs in FEP models to promote paid employment.
\end{abstract}

\section{Introduction}

Schizophrenia is one of the most debilitating mental disorders. For a significant portion of individuals who suffer from this disorder, onset occurs in young adulthood, arresting important social and educational development that is necessary for future successful labor force participation. As a result, schizophrenia is often associated with an eventual downward spiral ending in poverty and isolation[1]. To avert this dismal future, the focus on the first psychotic episode (FEP) is becoming a priority for mental health care globally (e.g., Johannessen et al. [2]).

There is also growing evidence surrounding the low employment rates of people with FEP. Employment rate estimates range from 13 to $55 \%$ [3-5]. Reviews of the literature $[3,6]$ note that there are a number of factors associated with employment along a number of dimensions [7-9]. Along with cognitive impairment and symptoms, educational attainment, family socioeconomic status, social benefit structures, and labour market conditions also potentially affect employment of young adults with first episode psychosis
[3]. There appears to be a complex mix of both individual and environmental factors linked to successful labour market participation. Although it is a multifaceted challenge, there is increasing evidence for the effectiveness of interventions such as Individual Placement and Support (IPS) programs and the interventions of vocational specialists for this population [4, 6, 10-13]. As such, the International First Episode Vocational Recovery (iFEVR) Group [14] released a consensus statement advocating for the "right to education, training and employment" for young people enrolled in early intervention programs.

The need for the iFEVR consensus statement is motivated by the mounting evidence that employment is often not a priority for providers who serve and support FEP clients. For example, Rinaldi and colleagues [6] note that few FEP studies have focused on employment and education outcomes. In fact, employment is often discouraged by well-intentioned medical professionals and family $[6,10,15]$. In addition, governments have been less than supportive of employment programs for people with mental illnesses [16]. 
The purpose of this paper is to contribute to the literature about clients enrolled in first episode psychosis programs and psychosocial outcomes by examining the factors associated with paid employment among young adults who have experienced their first psychotic episode. In this paper, we consider the association of socioeconomic factors with employment.

\section{Background}

2.1. Characteristics of FEP Programs. FEP programs are designed to facilitate recovery from psychotic illnesses that first arise during youth, most commonly schizophrenia and bipolar disorder, and have historically been most associated with very high levels of disability [17]. Programs are designed to provide services to both clients and their families. Services include comprehensive diagnostic assessment, treatment, psychosocial supports, as well as family education and support. There is emphasis on a multidisciplinary team approach that integrates medical treatment, counseling, case management, substance abuse treatment, cognitiv behavioural therapy, in addition to psychoeducation for families.

\subsection{Characteristics of the Study FEP Programs. The six FEP} programs included in this study were located in six regions throughout the province of Ontario, Canada. Each program accepted youth who were experiencing their first episode or early stages of psychosis. Each early intervention program was developed to exclusively provide outpatient services.

Five of the six FEP programs reported that nearly threequarters of their clientele were males. Three of the FEP programs engaged clients aged 14 to 35 years old, while the remaining three programs limited access to people who were at least 16 years old. Two FEP programs engaged transitional aged youth 16 to 23 years old.

All but one of the six programs were located in established community mental health agencies. The exception was a community-based program that was part of an acute care hospital. The number of staff members in each of the six programs varied considerably, ranging from three parttime positions to 10 full-time equivalent positions. Each of the FEP programs was developed in accordance with the guidelines and standards set forth by the International Early Psychosis Association and other pioneers in the field [17-20].

2.3. FEP Programs and Vocational Outcomes. There is evidence that compared to FEP clients who receive usual care, those enrolled in early intervention programs have significantly better educational and vocational outcomes [21]. The relatively better vocational outcomes associated with FEP programs may be associated with the shorter duration of untreated psychosis for these clients. Norman et al. [22] found that shorter duration of untreated psychosis and greater social support were significantly associated with either more full-time competitive work or full-time enrollment in school at three-year followup.

In their review, Rinaldi and colleagues [6] note that when compared to those enrolled in community mental health teams, clients enrolled in FEP program seem to experience a relatively smaller decline in employment and education.
They attribute this to a protective role played by FEP programs. Major et al. [5] observed a decrease in unemployment among FEP clients after 12 months even in the absence of a vocational focus.

However, there is less evidence regarding the long-run outcomes for FEP programs versus usual care. After 18 months, the LEO (Lambeth Early Onset team) study did not find [21] a significant difference between clients in specialize programs versus those who were not. After 5 years, the OPUS trial did not find significant differences in employment between clients who were in FEP versus usual care [23].

2.4. Work History and Employment. In the literature focusing on vocational outcomes in the adult population with severe and persistent mental disorders, it has been observed that work history is one of the most consistent predictors of employment [24]. However, because of their stage in life, young adults experiencing their first psychotic episode have not had the opportunity to accumulate labor force experience. This can place FEP clients at a disadvantage in finding paid employment.

2.5. Educational Attainment and Employment. The literature also indicates that educational attainment is significantly related to employment status. People who have no high school diploma are more likely to be unemployed $[25,26]$. If young people have their education interrupted by their illness, they can be faced with another disadvantage in finding employment.

2.6. Disability Benefits and Employment. There is also an association between receipt of disability benefits and unemployment $[10,27]$. The fear of losing disability benefits has been identified as one of the barriers to obtaining and maintaining employment for clients with severe mental illness $[3,24,28]$. As a result, those who receive benefits often have poorer employment experiences.

Thus, there is accumulating evidence suggesting that in addition to treatment in FEP programs, socioeconomic factors such as educational attainment and income sources also play a role in employment outcomes. This type of evidence can help to inform future directions for the enhancement of psychosocial programs in FEP models.

\section{Methods}

3.1. Data Collection. The study protocol was approved by the Centre for Addiction and Mental Health's Research Ethics Board. A cross-sectional data collection approach was used at three points in time during October 2005, 2006, and 2007 in six FEP programs located throughout Ontario, Canada's largest and most populous province.

Interview participation criteria included (1) willingness to be contacted by a study interviewer, (2) ability to understand and give informed consent to be interviewed, and (3) enrollment in one of the six participating FEP programs. Data were collected using face-to-face structured interviews 
TABLE 1: Characteristics of FEP clients who did and did not have paid employment during previous 12 months.

\begin{tabular}{|c|c|c|c|c|c|}
\hline \multirow[t]{2}{*}{ Characteristics } & \multicolumn{2}{|c|}{$\begin{array}{l}\text { Had paid employment during } \\
\text { the previous } 12 \text { months }\end{array}$} & \multicolumn{2}{|c|}{$\begin{array}{l}\text { Did not have paid employment } \\
\text { during the previous } 12 \text { months }\end{array}$} & \multirow{2}{*}{$\begin{array}{l}\text { Statistical tests for differences } \\
\text { between characteristics of employed } \\
\text { and unemployed }\end{array}$} \\
\hline & $\%$ or mean & $n$ or sd & $\%$ or mean & $n$ or sd & \\
\hline \multicolumn{6}{|l|}{ Sex } \\
\hline Male & $70.2 \%$ & 59 & $72.2 \%$ & 39 & \multirow{2}{*}{$\chi^{2}(1)=0.063, P=0.80$} \\
\hline Female & 29.8 & 25 & 27.8 & 15 & \\
\hline Age (in years) & 23.3 & $\mathrm{sd}=5.13$ & 21.93 & $\mathrm{sd}=3.98$ & $t$-test $(136)=-1.62, P=0.11$ \\
\hline No high school diploma & $24.1 \%$ & 20 & $44.4 \%$ & 24 & $\chi^{2}(1)=6.21, P=0.013$ \\
\hline \multicolumn{6}{|l|}{$\begin{array}{l}\text { Population density of } \\
\text { region of residence }\end{array}$} \\
\hline$\leq 100$ people $/ \mathrm{km}^{2}$ & $52.4 \%$ & 44 & $48.2 \%$ & 26 & $\chi^{2}(1)=0.24, P=0.63$ \\
\hline $200-450$ people $/ \mathrm{km}^{2}$ & 38.1 & 32 & 24.1 & 13 & $\chi^{2}(1)=2.94, P=0.086$ \\
\hline$\geq 3,929$ people $/ \mathrm{km}^{2}$ & 9.5 & 8 & 27.8 & 15 & $\chi^{2}(1)=7.89, P=0.0050$ \\
\hline Living with family & $66.7 \%$ & 56 & $66.7 \%$ & 36 & $\chi^{2}(1)=0.0, P=1.0$ \\
\hline $\begin{array}{l}\text { Enrolled in school } \\
\text { during the past } 12 \\
\text { months }\end{array}$ & $52.4 \%$ & 44 & $40.7 \%$ & 22 & $\chi^{2}(1)=1.78, P=0.18$ \\
\hline $\begin{array}{l}\text { Provincial } \\
\text { disability-benefits main } \\
\text { source of income }\end{array}$ & $17.7 \%$ & 14 & $59.2 \%$ & 29 & $\chi^{2}(1)=23.31, P<0.001$ \\
\hline $\begin{array}{l}\text { Enrolled in FEP } \\
\text { program }>1 \text { year }\end{array}$ & $37.8 \%$ & 31 & $28.3 \%$ & 15 & $\chi^{2}(1)=1.29, P=0.26$ \\
\hline
\end{tabular}

administered by trained interviewers. Potential study participants were referred by program case managers.

In 2005, the participating FEP programs referred 45 clients $(28 \%)$ of the total 161 enrolled, to be contacted by the study; of these, $33(73 \%)$ were successfully interviewed. They represented $20 \%$ of the total clients enrolled. In 2006, 106 $(32 \%)$ of 302 early intervention clients were eligible to be contacted by the study. There were $75(71 \%)$ who were successfully interviewed. They represented $25 \%$ of the total clients. In 2007, 162 (44\%) of 370 early intervention clients were eligible to be contacted for interviews. Of these, 107 (66\%) were successfully interviewed. These clients constituted $29 \%$ of the total early intervention clients enrolled in the six programs.

3.2. Dependent Variable. An indicator variable was created to capture whether or not study participants had paid employment during the previous 12 months.

3.3. Study Participant Characteristics. Indicator variables were created to capture whether the respondent was living with family (i.e., parent(s), sibling(s), and spouse), education (completed high school: yes/no), gender (male: yes/no), age at time of interview, receipt of provincial disability benefits as the primary income source (yes/no) and enrolled in school during the previous 12 months (yes/no). An indicator variable was also created to capture whether participants were enrolled in their FEP program for more than a year.

Three region indicator variables were created to capture the population density of the region in which the participant lived. Region 1 indicated that the participant resided in a region in which the population density was less than 100 people $/ \mathrm{km}^{2}$. Region 2 indicated that the region of residence had a population density between 200 and 450 people $/ \mathrm{km}^{2}$. Finally, Region 3 indicated that the region of residence had 3,929 people $/ \mathrm{km}^{2}$.

3.4. Analyses. Descriptive statistics were used to test for significant differences in the characteristics of people who had paid employment during the previous 12 months. Chisquare and Fisher exact tests were used to test the differences between the categorical variables.

Logistic regression analysis was used to identify the factors associated with having had paid employment. The most parsimonious model was used based on the factors described in the literature that are associated with employment for people with serious mental illnesses.

\section{Results}

About $61 \%$ of the sample had paid employment during the previous 12 months. In Table 1, compared to those who did not have employment, among those who had employment, there was a significantly greater proportion of people with at least a high school diploma $\left(\chi^{2}(2)=6.21, P=0.013\right)$ and a significantly lower proportion who identified provincial disability benefits as their primary income source $\left(\chi^{2}(2)=\right.$ 23.31, $P<0.0001)$.

Table 2 contains the results of the logistic regression analysis. The regression model produced $83.2 \%$ concordant and $16.6 \%$ discordant predicted probabilities and observed responses. The Hosmer and Lemeshow Goodness-of-Fit Test 
TABLE 2: Logistic regression results: outcome = paid employment during past 12 months.

\begin{tabular}{|c|c|c|}
\hline Variables & Odds ratio & $P$ value \\
\hline Male (reference group: females) & 0.78 & 0.64 \\
\hline Age (in years) & 1.12 & 0.10 \\
\hline No high school diploma (reference group: has high school diploma) & 0.34 & 0.045 \\
\hline \multicolumn{3}{|l|}{ Population density of region of residence } \\
\hline \multicolumn{3}{|l|}{ (Reference group: $<100$ people $/ \mathrm{km}^{2}$ ) } \\
\hline $200-450 / \mathrm{km}^{2}$ & 2.73 & 0.062 \\
\hline$\geq 3,929 / \mathrm{km}^{2}$ & 1.21 & 0.78 \\
\hline Living with family (reference group: not living with family) & 0.46 & 0.15 \\
\hline $\begin{array}{l}\text { Enrolled in school during the past } 12 \text { months } \\
\text { (reference group: not enrolled in school in past } 12 \text { months) }\end{array}$ & 1.29 & 0.62 \\
\hline $\begin{array}{l}\text { Provincial disability-benefits main source of income } \\
\text { (reference group: provincial disability benefits not main source of income) }\end{array}$ & 0.069 & $<0.0001$ \\
\hline $\begin{array}{l}\text { Enrolled in FEP program }>1 \text { year } \\
\text { (Reference group: enrolled in FEP program } \leq 1 \text { year) }\end{array}$ & 3.014 & 0.045 \\
\hline $\begin{array}{r}\chi^{2}(9)=44.32, P< \\
R^{2}=0.30 \\
n=124\end{array}$ & & \\
\hline
\end{tabular}

was $\chi^{2}(8)=10.99, P=0.202$. These results indicate that the null hypothesis cannot be rejected; the model fits the data and the model has adequate goodness-of-fit.

The results suggest that the odds of having been employed in the past 12 months are significantly lower for people who have not completed high school $(\mathrm{OR}=0.34,95 \%$ $\mathrm{CI}=0.12,0.97)$ and for clients who identified provincial disability benefits as their primary income source $(\mathrm{OR}=0.069$, $95 \% \mathrm{CI}=0.022,0.21)$. There is also a significant positive association between employment and being enrolled in the FEP program for more than a year $(\mathrm{OR}=3.014,95 \%$ $\mathrm{CI}=1.027,8.85)$.

\section{Discussion}

In our sample, $61 \%$ of respondents had paid employment during the previous 12 months. This proportion is greater than that reported in the literature. For example, Singh et al. [29] observed that among the cohort of FEP clients, the past year employment rate (either full or part time) was $31.3 \%$. Similarly, Norman et al. [22] reported employment rates of $44 \%$, while Turner et al. [30] reported an employment rate of $46 \%$.

We also observed a significant difference between the educational attainment of those who were employed and those who were not. Educational attainment is a significant concern among FEP clients [10, 11]. Norman et al. [22] observed that $46 \%$ of clients in their sample had attained less than a high school education at time of program entry. Assessing the three-year outcomes of FEP clients, Singh et al. [29] reported that 53.6\% participants had not attained their secondary education certificates.

Our regression results underscore one of the major problems associated with the lack of educational attainment; educational attainment is associated with the ability to attain employment. Our results indicate that those who did not complete high school were less likely to be employed. This association corroborates what has been reported in literature $[5,31]$. These results echo the need highlighted by Cook [32] in her review of the literature that a significant proportion of people with serious and persistent mental disorders have their education interrupted by the onset of mental disorders. That is, people with severe mental illness are likely to have lower educational attainment than their counterparts who have not experienced a mental disorder. In turn, this places them at a disadvantage to successfully compete in the labor market.

One of the arguments for early labour market participation is because of its effect on future employment. In their longitudinal study of people with severe mental illness, Bush and colleagues [33] found that those who were employed at the beginning of a 10-year period were more likely to remain steadily employed throughout. In contrast, those who were not employed at the beginning were more likely to remain unemployed throughout the period. It should be noted that Bush et al. [33] looked at a group of people with severe mental illness. It will be important for future studies to examine effects of early employment in the FEP population.

Our regression results also indicate that enrollment in a FEP program for more than a year is significantly associated with employment. That is, clients who have been enrolled in a FEP program for more than a year are three times more likely to have been employed during the year than clients who were enrolled for less than a year. This is a trend that has been reported in the literature. After a three-year followup of FEP clients, Singh et al. [29] saw past 12-month employment rates increase from $25.3 \%$ at intake to $31.3 \%$ at followup. This could be reflective of the protective effect provided by FEP programs [6]. 
None of the FEP programs that participated in this study had vocational specialists. This suggests that vocational outcomes were not necessarily one of the main foci of the programs. Yet, there was improvement in vocational outcomes. At the same time, compared to FEP programs without a vocational focus, those with IPS programs and vocational specialists have reported relatively better vocational outcomes $[4,6,10-13]$. Thus, although FEP programs appear to provide a protective effect, there is evidence that with a vocational focus, they can be more than protective.

Finally, these results suggest that enrolment in a public disability benefit program also decreases the likelihood of being employed. Our results may reflect the fact that the people who receive disability benefits are too ill to be employed. Alternatively, the results could also be related to incentives associated with receipt of disability benefits. In her review of the literature, Cook [32] points out that few people leave public disability benefits due to employment. Our finding corroborates findings that disability benefits are inversely associated with employment rates. That is, as disability benefit levels decrease, employment rates increase, and the use of unemployment benefits decreases [34]. This suggests that publicly funded benefits may inadvertently create disincentives to work. For example, people might perceive that they will be penalized for working. In Ontario, the province in which this study was conducted, when people are employed and also receive benefits from the provincial disability support program, the program calculates half of the client's net monthly earnings, deducts part or all of his/her monthly child care and disability-related work costs, and subtracts this amount from the client's total income support [35]. Although in theory the earned income should substitute for income support, people who receive disability benefits and who work will see their disability income support decreased but not necessarily associate the decrease with their pay check.

At the same time, the provincial disability benefit program also seeks to create an incentive for paid employment by offering clients an additional monthly $\$ 100$ work-related benefit [35] if they are employed in a paid position. Yet, the incentive to work may not be sufficient if people are unsure about their long-term ability to maintain employment. There may still be a fear that if they lose their disability benefits, they will be without a safety net if they lose their jobs [3638]. It will be important for future research to explore the mechanisms of designing safety nets that ensure that when people are unable to work, they will have income while encouraging employment when it is possible. It will also be a challenge for FEP programs to design programs that help clients to receive training for jobs in business sectors in which they can earn a living wage [32] and that can accommodate episodes of illness so clients can accumulate successful employment histories.

Limitations. The results of this study should be considered in the light of its limitations. One of its major limitations relates to its generalizability. The clients who participated in these interviews may not necessarily be representative of all clients in FEP programs. Given that only clients who were able to provide informed consent were asked to participate, those who were the most sick would have been omitted. Thus, our results are a conservative estimate of the proportion who were unemployed if the most severely ill were more likely to be unemployed. Likewise, the regression results reflect associations for less severely ill people and may differ for the more severely ill; however, the latter group may also be less likely to be seeking employment.

In addition, the sample only included people who were enrolled in early intervention for psychosis programs. Results may be different for people experiencing their first psychotic episode who do not receive services from a program specializing in first psychotic episode cases.

\section{Conclusions}

There is little in the literature focusing on employment in the FEP population examining the contribution of socioeconomic factors to employment status. The results of our analyses indicate that receipt of public disability benefits and high school education are important factors related to employment. They also suggest that if paid employment is to be used as one measure of psychosocial outcomes, it is an outcome that may require cross-sector collaboration among health, education, and social services.

\section{Acknowledgments}

The authors are grateful for the excellent research assistance provided by the Matryoshka Coordinating team as well as all the interviewers and the Centre for Addiction and Mental Health's regional staff. The authors would also like to gratefully acknowledge the participation of the programs and interview participants who supported this project and who were willing to so generously share their experiences with them. This paper has also greatly benefited from the comments and suggestions of the anonymous reviewers. This project was funded by the Ontario Mental Health Foundation and the Social Sciences and Humanities Research Council of Canada. C. S. Dewa also gratefully acknowledges the support provided by her CIHR/PHAC Applied Public Health Chair. The Centre for Addiction and Mental Health receives funding from the Ontario Ministry of Health and Long-Term Care to support research infrastructure. Any remaining errors are the sole responsibility of the authors and do not reflect the views of any of the funders.

\section{References}

[1] W. Löffler and H. Häfner, "Ecological pattern of first admitted schizophrenics in two German cities over 25 years," Social Science and Medicine, vol. 49, no. 1, pp. 93-108, 1999.

[2] J. O. Johannessen, T. H. McGlashan, T. K. Larsen et al., "Early detection strategies for untreated first-episode psychosis," Schizophrenia Research, vol. 51, no. 1, pp. 39-46, 2001.

[3] S. Marwaha and S. Johnson, "Schizophrenia and employment: a review," Social Psychiatry and Psychiatric Epidemiology, vol. 39, no. 5, pp. 337-349, 2004.

[4] M. Rinaldi, K. McNeil, M. Firn, M. Koletsi, R. Perkins, and S. P. Singh, "What are the benefits of evidence-based supported 
employment for patients with first-episode psychosis?" Psychiatric Bulletin, vol. 28, no. 8, pp. 281-284, 2004.

[5] B. S. Major, M. F. Hinton, A. Flint, A. Chalmers-Brown, K. McLoughlin, and S. Johnson, "Evidence of the effectiveness of a specialist vocational intervention following first episode psychosis: a naturalistic prospective cohort study," Social Psychiatry and Psychiatric Epidemiology, vol. 45, no. 1, pp. 1-8, 2010.

[6] M. Rinaldi, E. Killackey, J. Smith, G. Shepherd, S. P. Singh, and T. Craig, "First episode psychosis and employment: a review," International Review of Psychiatry, vol. 22, no. 2, pp. 148-162, 2010.

[7] A. D. Henry and A. M. Lucca, "Facilitators and barriers to employment: the perspectives of people with psychiatric disabilities and employment service providers," Work, vol. 22, no. 3, pp. 169-182, 2004.

[8] K. T. Mueser, R. E. Clark, M. Haines et al., "The Hartford study of supported employment for persons with severe mental illness," Journal of Consulting and Clinical Psychology, vol. 72, no. 3, pp. 479-490, 2004.

[9] S. R. McGurk and K. T. Mueser, "Cognitive functioning, symptoms, and work in supported employment: a review and heuristic model," Schizophrenia Research, vol. 70, no. 2-3, pp. 147-173, 2004.

[10] E. J. Killackey, H. J. Jackson, J. Gleeson, I. B. Hickie, and P. D. McGorry, "Exciting career opportunity beckons! Early intervention and vocational rehabilitation in first-episode psychosis: employing cautious optimism," Australian and New Zealand Journal of Psychiatry, vol. 40, no. 11-12, pp. 951-962, 2006.

[11] K. H. Nuechterlein, K. L. Subotnik, L. R. Turner, J. Ventura, D. R. Becker, and R. E. Drake, "Individual placement and support for individuals with recent-onset schizophrenia: integrating supported education and supported employment," Psychiatric Rehabilitation Journal, vol. 31, no. 4, pp. 340-349, 2008.

[12] M. Rinaldi, R. Perkins, E. Glynn, T. Montibeller, M. Clenaghan, and J. Rutherford, "Individual placement and support: from research to practice," Advances in Psychiatric Treatment, vol. 14, no. 1, pp. 50-60, 2008.

[13] E. Killackey, H. J. Jackson, and P. D. McGorry, "Vocational intervention in first-episode psychosis: individual placement and support v. treatment as usual," British Journal of Psychiatry, vol. 193, no. 2, pp. 114-120, 2008.

[14] E. Killackey, "Meaningful lives: supporting young people with psychosis in education, training and employment: an international consensus statement," Early Intervention in Psychiatry, vol. 4, no. 4, pp. 323-326, 2010.

[15] S. Marwaha and S. Johnson, "Views and experiences of employment among people with psychosis: a qualitative descriptive study," International Journal of Social Psychiatry, vol. 51, no. 4, pp. 302-316, 2005.

[16] G. R. Bond, D. R. Becker, R. E. Drake et al., "Implementing supported employment as an evidence-based practice," Psychiatric Services, vol. 52, no. 3, pp. 313-322, 2001.

[17] Ontario Ministry of Health and Long-Term Care, Early Psychosis Intervention Program Standards, Ontario Ministry of Health and Long-Term Care, Toronto, Canada, 2011.

[18] J. Bertolote and P. McGorry, "Early intervention and recovery for young people with early psychosis: consensus statement," British Journal of Psychiatry, vol. 187, no. 48, pp. s116-s119, 2005.

[19] J. Edwards and P. McGorry, "Developing an early psychosis service-'nuts and bolts', in Implementing Early Intervention in Psychosis: A Guide to Establishing Early Psychosis Services,
J. Edwards and P. McGorry, Eds., pp. 85-106, Martin Dunitz, London, UK, 2002.

[20] International Early Psychosis Association Writing Group, "International clinical practice guidelines for early psychosis," British Journal of Psychiatry, vol. 187, pp. 120-124, 2005.

[21] P. A. Garety, T. K. J. Craig, G. Dunn et al., "Specialised care for early psychosis: symptoms, social functioning and patient satisfaction-randomised controlled trial," British Journal of Psychiatry, vol. 188, pp. 37-45, 2006.

[22] R. M. G. Norman, A. K. Mallal, R. Manchanda et al., "Does treatment delay predict occupational functioning in firstepisode psychosis?" Schizophrenia Research, vol. 91, no. 1-3, pp. 259-262, 2007.

[23] M. Bertelsen, P. Jeppesen, L. Petersen et al., "Five-year followup of a randomized multicenter trial of intensive early intervention versus standard treatment for patients with a first episode of psychotic illness : the OPUS trial," Archives of General Psychiatry, vol. 65, no. 7, pp. 762-771, 2008.

[24] K. Campbell, G. R. Bond, R. E. Drake, G. J. McHugo, and $\mathrm{H}$. Xie, "Client predictors of employment outcomes in highfidelity supported employment: a regression analysis," Journal of Nervous and Mental Disease, vol. 198, no. 8, pp. 556-563, 2010.

[25] L. Harvey, "New realities: the relationship between higher education and employment," Tertiary Education and Management, vol. 6, no. 1, pp. 3-17, 2000.

[26] Statistics Canada, Employment Rates, Educational Attainment, Statistics Canada, Ottawa, Canada, 2010.

[27] B. C. Ho, N. Andreasen, and M. Flaum, "Dependence on public financial support early in the course of schizophrenia," Psychiatric Services, vol. 48, no. 7, pp. 948-950, 1997.

[28] M. McQuilken, J. H. Zahniser, J. Novak, R. D. Starks, A. Olmos, and G. R. Bond, "The work project survey: consumer perspective on work," Journal of Vocational Rehabilitation, vol. 18, no. 1, pp. 59-68, 2003.

[29] S. P. Singh, T. Croudace, S. Amin et al., "Three-year outcome of first-episode psychoses in an established community psychiatric service," British Journal of Psychiatry, vol. 176, pp. 210-216, 2000.

[30] N. Turner, S. Browne, M. Clarke et al., "Employment status amongst those with psychosis at first presentation," Social Psychiatry and Psychiatric Epidemiology, vol. 44, no. 10, pp. 863869, 2009.

[31] G. Waghorn, D. Chant, and H. Whiteford, "The strength of self-reported course of illness in predicting vocational recovery for persons with schizophrenia," Journal of Vocational Rehabilitation, vol. 18, no. 1, pp. 33-41, 2003.

[32] J. A. Cook, "Employment barriers for persons with psychiatric disabilities: update of a report for the president's commission," Psychiatric Services, vol. 57, no. 10, pp. 1391-1405, 2006.

[33] P. W. Bush, R. E. Drake, H. Xie, G. J. McHugo, and W. R. Haslett, "The long-term impact of employment on mental health service use and costs for persons with severe mental illness," Psychiatric Services, vol. 60, no. 8, pp. 1024-1031, 2009.

[34] E. Westerhout, "Disability risk, disability benefits, and equilibrium unemployment," International Tax and Public Finance, vol. 8, no. 3, pp. 219-243, 2001.

[35] Ontario Ministry of Community and Social Services, Ontario Disability Benefits, Ontario Ministry of Community and Social Services, Toronto, Canada, 2010.

[36] C. S. Dewa and D. McDaid, "Investing in the mental health of the labor force: epidemiological and economic impact of mental disorders in the workplace," in Handbook of Job 
Accomodation on Mental Health, I. Schultz and E. Rogers, Eds., Springer, New York, NY, USA, 2009.

[37] K. L. MacDonald-Wilson, E. S. Rogers, M. L. Ellison, and A. Lyass, "A study of the social security work incentives and their relation to perceived barriers to work among persons with psychiatric disability," Rehabilitation Psychology, vol. 48, no. 4, pp. 301-309, 2003.

[38] S. Magura, "The role of work in substance dependency treatment: a preliminary overview," Substance Use and Misuse, vol. 38, no. 11-13, pp. 1865-1876, 2003. 


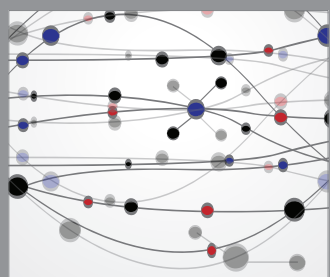

The Scientific World Journal
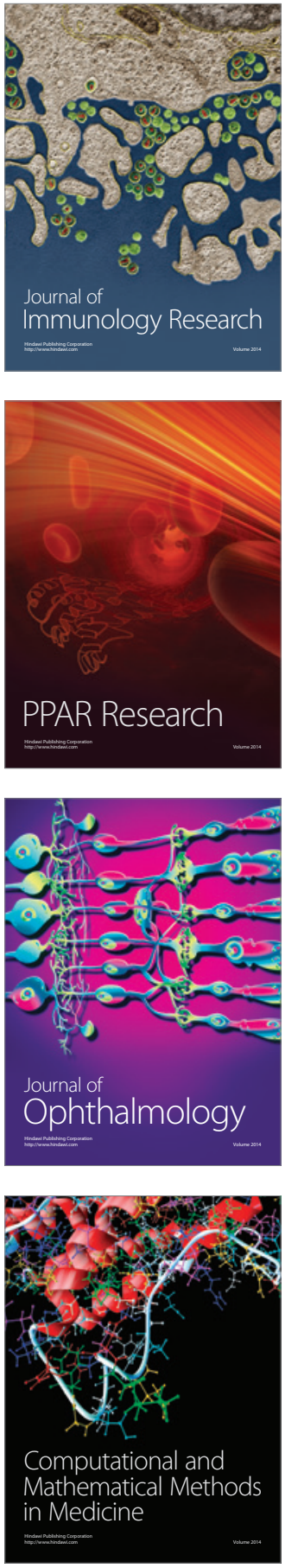

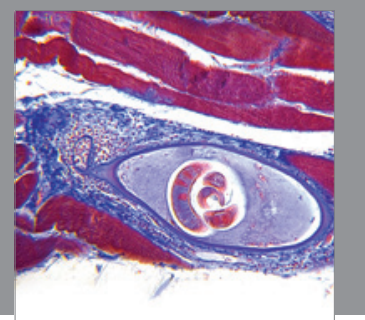

Gastroenterology

Research and Practice
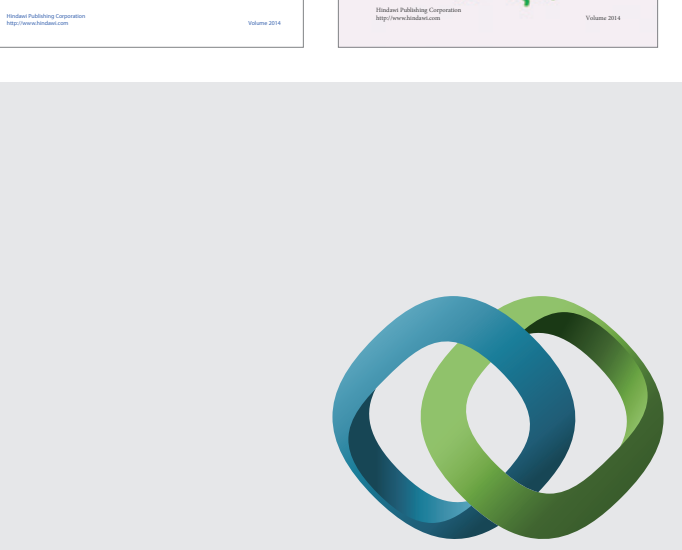

\section{Hindawi}

Submit your manuscripts at

http://www.hindawi.com
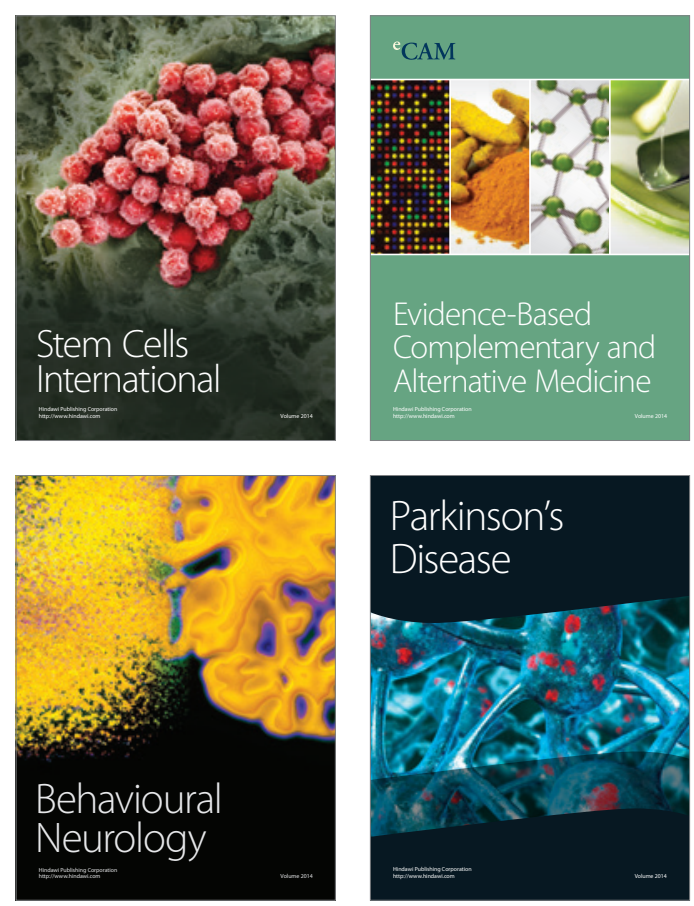

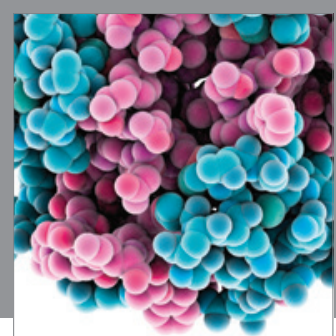

Journal of
Diabetes Research

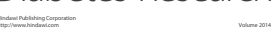

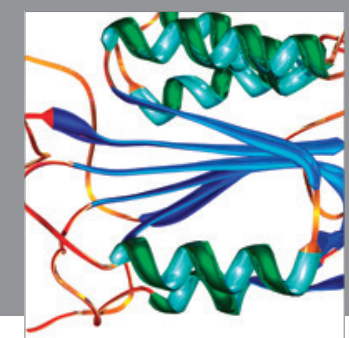

Disease Markers
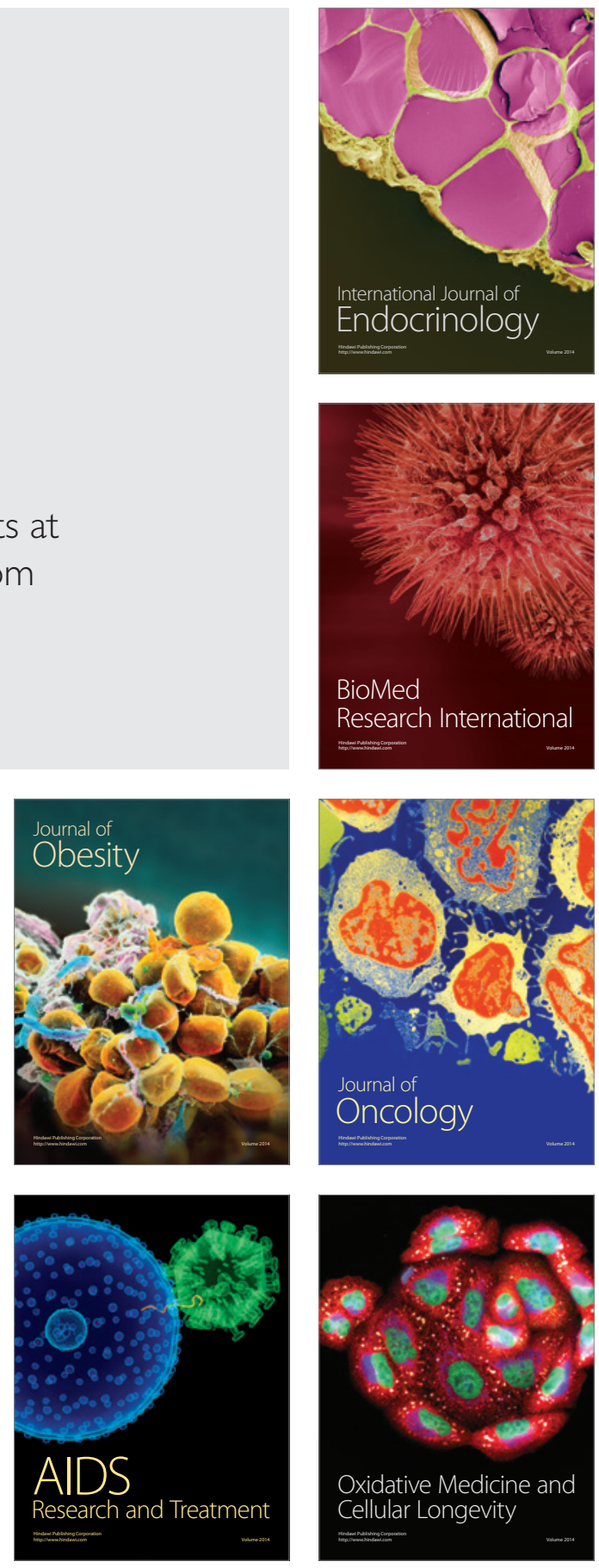